\title{
Un hidrogel de hidróxido de aluminio para eliminar el arsénico del agua
}

\author{
Juan Carlos Luján ${ }^{1}$
}

RESUMEN Objetivos. Describir la sintesis y los resultados preliminares de la aplicación de un hidrogel de hidróxido de aluminio que, agregado directamente al agua, pueda lograr la eliminación total del arsénico, cualquiera que sea la naturaleza del agua y el estado de oxidación del metaloide. Métodos. Las materias primas utilizadas para obtener el hidrogel de hidróxido de aluminio fueron: sulfato de aluminio hidratado (que se utiliza para potabilizar aguas), hipoclorito de calcio en polvo, hidróxido de amonio y agua destilada (cuando el gel se preparó a escala de laboratorio) y agua de ósmosis inversa de igual o mejor calidad que el agua destilada (cuando se produjo el gel a escala piloto). El control de calidad del producto final consistió en la determinación de su capacidad para adsorber el arsénico y la realización de pruebas bacteriológicas para demostrar su esterilidad. El producto fue aplicado a muestras de agua a las que se añadió arsénico en el laboratorio y a muestras de aguas arsenicales naturales procedentes de la provincia de Tucumán, Argentina. Para el análisis del arsénico en el agua se utilizó el método colorimétrico del dietilditiocarbamato de plata.

Resultados. La aplicación del hidrogel proporcionó una gran reducción del arsénico. Tanto en las aguas arsenicales naturales como en las artificiales, después del tratamiento las concentraciones de arsénico quedaron por debajo del límite de detección del método analítico utilizado (0,01 partes por millón). Las pruebas bacteriológicas del producto terminado revelaron la ausencia de bacterias viables.

Conclusiones. La aplicación del hidrogel de hidróxido de aluminio proporcionó la deseada reducción de la concentración de arsénico en el agua. Este método de desarsenización es barato y fácil de utilizar en poblaciones rurales dispersas de zonas afectadas por el hidroarsenicismo que carecen de agua potable e infraestructura sanitaria y eléctrica.

Palabras clave Hidroarsenicismo, adsorción, desarsenización, potabilización, calidad del agua.

El problema del hidroarsenicismo de origen geológico-sedimentario (1, 2) no es nuevo y afecta a varias provincias de la Argentina, principalmente en zonas rurales carentes de redes de distribución de agua potable. Se estima que en la provincia de Tucumán hay unas 30000 personas expues-

\footnotetext{
1 Universidad Tecnológica Nacional, Facultad Regional Tucumán, Argentina. Rivadavia 1050 - (4000), San Miguel de Tucumán, Tucumán, Argentina.
}

tas a beber aguas contaminadas con arsénico (3). También se lo detecta en algunas regiones de países como México, Chile y otros (4).

El arsénico, aun en concentraciones muy bajas (vestigios), puede causar a largo plazo enfermedades neoplásicas malignas, queratosis palmoplantar, atrofia cutánea, conjuntivitis, astenia o trastornos neurológicos y hematológicos, entre otros, lo que justifica la decisión de la Organización Mundial de la Salud (OMS) de reducir cinco veces el límite máximo admisible: de 0,05 a 0,01 ppm (partes por millón).

A lo largo del tiempo se han ensayado diferentes técnicas para reducir el arsénico del agua, entre ellas la destilación solar, la osmosis inversa y el paso del agua arsenical por mantos filtrantes de propiedades adsorbentes, tales como alúmina activada, huesos de vacuno calcinados o virutas de hierro parcialmente oxidado (5). En el Laboratorio de la Universidad Tecnológica Nacional también se han probado 
métodos electroquímicos consistentes en la liberación de partículas coloidales de hidróxido de aluminio partiendo de la erosión de electrodos de cinc o de aluminio, y se obtuvieron rendimientos superiores al $99 \%$ en la remoción del arsénico, aunque se presentaron problemas de contaminación del agua por impurezas asociadas al material de los electrodos. Asimismo, se ha intentado tratar las aguas arsenicales por electrodiálisis, pero no se han encontrado membranas con poros de tamaño adecuado para eliminar selectivamente el arsénico.

El Centro Panamericano de Ingeniería Sanitaria (CEPIS) desarrolló un polvo compuesto por una mezcla de sulfato de aluminio, hipoclorito de calcio y arcilla activada que, agregado al agua, elimina el arsénico con una eficiencia variable que depende de las características fisicoquímicas del agua. En aguas arsenicales de la provincia de Tucumán, dicho producto mostró una eficiencia variable, de 45 a $65 \%$, según la procedencia del agua.

Con el objetivo de simplificar el tratamiento de las aguas arsenicales, en este artículo se describen la síntesis y los resultados preliminares de la aplicación de un coloide alumínico que, agregado directamente al agua, pueda lograr una eliminación total del arsénico, cualquiera que sea la naturaleza del agua y el estado de oxidación del metaloide.

\section{MATERIALES Y MÉTODOS}

Las materias primas utilizadas para obtener el hidrogel de hidróxido de aluminio son: sulfato de aluminio hidratado $\left(x 18 \mathrm{H}_{2} \mathrm{O}\right)$, utilizado para potabilización de aguas; hipoclorito de calcio en polvo, calidad puro, utilizado para clorar aguas; hidróxido de amonio 15 molar de densidad $0,9 \mathrm{~g} / \mathrm{cm}^{3}$, calidad reactivo químico, y agua destilada. La fórmula de la reacción química de obtención del hidróxido de aluminio es (6)

$$
\begin{gathered}
\mathrm{Al}_{2}\left(\mathrm{SO}_{4}\right)_{3}+6 \mathrm{NH}_{4}(\mathrm{OH}) \leftarrow \\
3 \mathrm{SO}_{4}\left(\mathrm{NH}_{4}\right)_{2}+2 \mathrm{Al}(\mathrm{OH})_{3}
\end{gathered}
$$

y el procedimiento consta de los siguientes pasos (figura 1):

- Se prepara una solución concentrada de sulfato de aluminio en agua, con $\mathrm{pH}$ 5,0 para evitar la hidrólisis de esta sal, y se calienta a $66^{\circ} \mathrm{C}$.

- Se agrega lentamente una solución de hidróxido de amonio para provocar la precipitación del gel de hidróxido de aluminio siguiendo continuamente el valor del $\mathrm{pH}$ hasta lograr el punto óptimo de hidrólisis del sulfato de aluminio y la adecuada activación de las partículas coloidales obtenidas (6).

- Se lava el hidrogel con agua obtenida por ósmosis inversa a presiones de $20 \mathrm{~atm}$, cuya pureza puede ser igual o superior a la del agua destilada convencional, hasta que el efluente de lavado presente valores nulos de sulfatos y amonio.
- Se añade hipoclorito de calcio en polvo en dosis suficiente para que, una vez aplicado el hidrogel al agua, produzca una concentración de 1 ppm de cloro libre, con el fin de garantizar la calidad bacteriológica del agua.

- Se envasa el hidrogel en una manga plástica, fraccionándolo en unidades de $5 \mathrm{~mL}$, y se esteriliza con vapor fluente durante 30 minutos.

Las materias primas y el producto terminado fueron sometidos a una serie de pruebas para asegurar su calidad:

- Control del título de las tres materias primas básicas: sulfato de aluminio, hidróxido de amonio e hipoclorito de calcio.

- Control de la pureza química y bacteriológica del agua de fabricación y lavado del hidrogel.

- Control del pH de estabilización del hidróxido de aluminio.

FIGURA 1. Representación esquemática de la preparación del hidrogel de hidróxido de aluminio a escala piloto

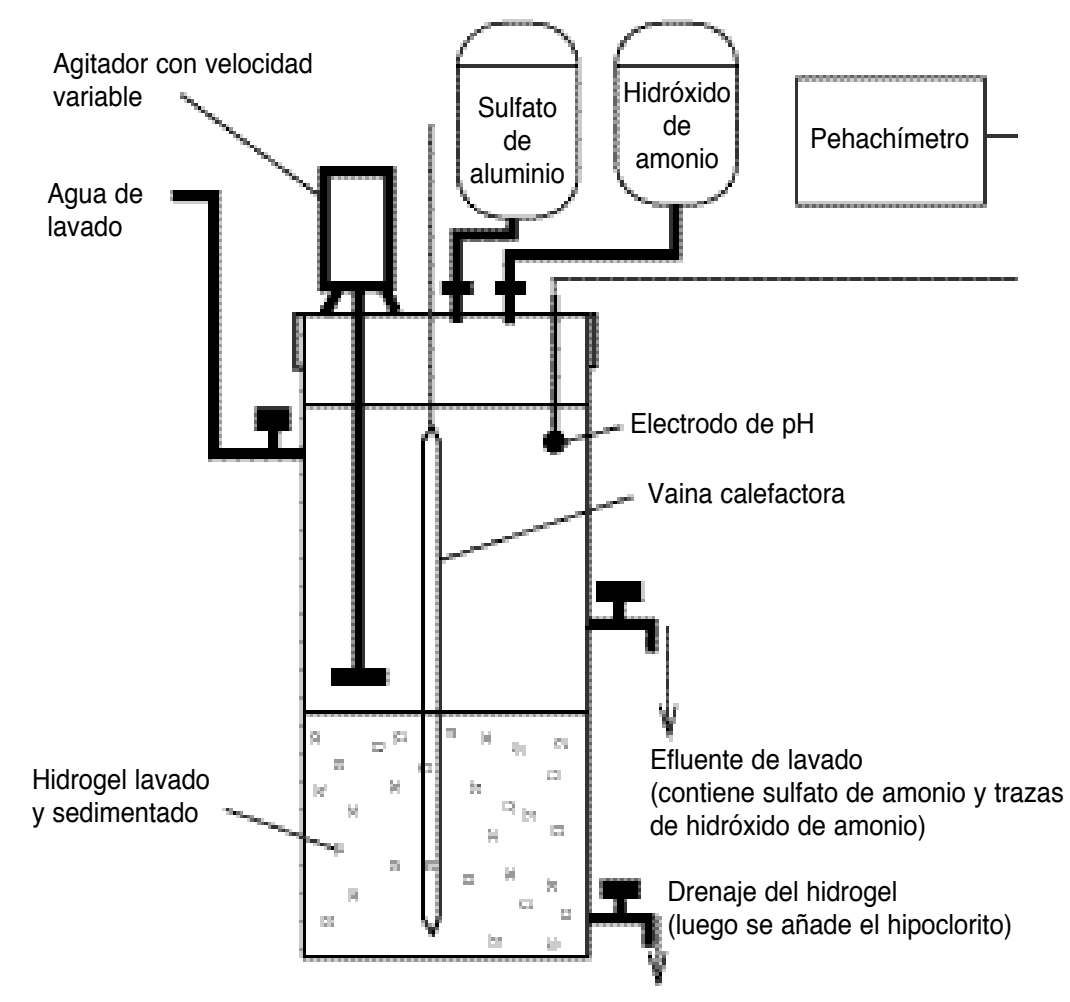


- Prueba de eliminación de sulfatos (mediante cloruro de bario en medio ácido) y de amonio (mediante el reactivo de Nessler) para comprobar la eficiencia del lavado del hidrogel.

- Control de calidad del producto final mediante la determinación de su capacidad para adsorber el arsénico y control bacteriológico con recuento total de bacterias aerobias mesófilas (siembra de $1 \mathrm{~mL}$ de agua en placa de agar triptona soja), recuento de coliformes (concentración de $100 \mathrm{~mL}$ de agua en membranas con poros de $0,45 \mu \mathrm{m}$ y cultivo en agar de McConkey) y recuento de Pseudomonas aeruginosa (concentración de $100 \mathrm{~mL}$ de agua en membranas con poros de $0,45 \mu \mathrm{m}$ y cultivo en agar cetrimida)

Los controles bacteriológicos se practicaron con agua estéril que había sido tratada con el hidrogel de la misma manera que se haría con una muestra de agua arsenical. Para el análisis del arsénico en el agua se utilizó el método colorimétrico del dietilditiocarbamato de plata (7), que permite detectar concentraciones de arsénico superiores a 0,01 ppm. Las muestras de aguas arsenicales naturales se tomaron en botellas plásticas de PET (polietilentereftalato) y se conservaron con $1 \mathrm{~mL}$ de ácido clorhídrico concentrado por cada litro de agua hasta su traslado al laboratorio. Hasta ahora se han analizado unas 200 muestras de aguas naturales tratadas con este método, cuyas concentraciones iniciales de arsénico estaban comprendidas entre 0,04 y $1,2 \mathrm{ppm}$.

La forma de aplicar el hidrogel de hidróxido de aluminio consiste en agregar el contenido de una bolsa de $5 \mathrm{~mL}$ por cada litro de agua y agitar vigorosamente el recipiente durante 1 minuto. Luego se deja reposar durante 3 horas o más, aunque lo más conveniente es realizar esta preparación durante la noche y dejar reposar el agua hasta el día siguiente; al extraer el sedimento el agua puede consumirse. El sedimento se desecha.

Se estima que por cada cinco mil moléculas de $\mathrm{Al}(\mathrm{OH})_{3}$ se adsorbería un átomo de arsénico.

CUADRO 1. Efecto del tratamiento sobre la concentración de arsénico en aguas arsenicales artificiales y naturales. Tucumán, Argentina, 2000

\begin{tabular}{lcc}
\hline & \multicolumn{2}{c}{$\begin{array}{c}\text { Concentración de arsénico } \\
\text { (partes por millón) }\end{array}$} \\
\cline { 2 - 3 } Muestras de agua & $\begin{array}{c}\text { Antes del } \\
\text { tratamiento }\end{array}$ & $\begin{array}{c}\text { Después del } \\
\text { tratamiento }\end{array}$ \\
\hline Agua artificial & 0,1 & $<0,01$ \\
Agua artificial & 0,5 & $<0,01$ \\
Agua artificial & 1,0 & $<0,01$ \\
Agua artificial & 5,0 & $<0,01$ \\
Aguas naturales & 0,04 a 0,10 & $<0,01$ \\
Aguas naturales & 0,10 a 0,45 & $<0,01$ \\
Aguas naturales & 0,45 a 0,60 & $<0,01$ \\
Aguas naturales & 0,60 a 0,80 & $<0,01$ \\
\hline a Las muestras artificiales se prepararon con agua potable de la red libre de arsénico, \\
añadiéndole una cantidad conocida de arsénico. Las muestras artificiales se analizaron \\
por cuadruplicado para cada concentración y se utilizaron cuatro clases de reactivos \\
químicos con el arsénico en distintos estados de oxidación (metaarsenito de sodio, ar- \\
seniato de sodio, trióxido de arsénico y dihidrógeno arseniato de sodio), de modo que, \\
en total, se analizaron 64 muestras. Las muestras naturales, procedentes de distintas \\
zonas de Tucumán afectadas por el hidroarsenicismo, están agrupadas en cuatro in- \\
tervalos de concentración y cada grupo contiene 50 muestras.
\end{tabular}

\section{RESULTADOS}

Al aplicar el hidrogel a muestras de aguas arsenicales artificiales y a muestras naturales de la provincia de Tucumán se obtuvieron los resultados que figuran en el cuadro 1 . Se observa una gran reducción del arsénico en ambos tipos de aguas. El método resulta exitoso para reducir el arsénico por debajo del límite de detección del método analítico $(0,01 \mathrm{ppm})$ tanto en aguas naturales con las máximas concentraciones registradas en la provincia como en aguas contaminadas artificialmente con concentraciones de arsénico cinco veces superiores a las naturales.

Las pruebas bacteriológicas (8) del producto terminado mostraron en 30 ensayos recuentos totales de bacterias nulos utilizando siembra en placas de agar de triptona soja. Tampoco hubo crecimiento en los cultivos de agua por concentración en membranas para la detección de $P$. aeruginosa en agar cetrimida ni de coliformes en agar de McConkey. La eliminación de bacterias en las muestras de aguas naturales tratadas no se ha estudiado todavía.

Las experiencias de laboratorio y de campo demostraron que el gel se com- pacta muy bien en el fondo de la botella, de tal modo que puede extraerse el agua sobrenadante con poco riesgo de arrastrar el sedimento. No obstante, se está probando un modelo experimental de un recipiente con válvula de drenaje en la base que permita extraer el sedimento y dejar el agua tratada cómodamente disponible en su interior.

El hidrogel mantiene su actividad durante más de 9 meses, aunque se presume que, protegido de la luz solar directa, su estabilidad puede ser de varios años.

\section{DISCUSIÓN}

La aplicación del método propuesto puede resolver de forma sencilla y económica el problema de las aguas arsenicales en zonas de población dispersa. Se estima que, de todos los intentos realizados en la región norte de la Argentina para brindar al habitante rural agua libre de arsénico, esta propuesta resulta económicamente viable por su reducido costo, en comparación con la distribución de aguas bromatológicas envasadas o el tratamiento del agua arsenical con equipos convencionales (ósmosis- 
destilación y otros). El costo de cada litro de agua tratada se calcula en US\$ 0,08 cuando se produce el hidrogel a una escala suficiente para abastecer a una población de 30000 habitantes.

Además, experiencias recientes permiten suponer que el hidrogel de hidróxido de aluminio también puede adsorber otros metales disueltos en el agua, como el cromo, el molibdeno y otros. El agregado del agente clorógeno cubre la necesidad de desinfección normal del agua, obteniéndose valores de cloro residual superiores a
0,5 ppm e inferiores a 1,0 ppm. No obstante, por el momento todavía no se han realizado controles microbiológicos de las muestras de aguas naturales tratadas.

En caso de ingestión accidental del sedimento, no son de esperar efectos adversos mayores que los que pudiera ocasionar el agua sin tratar, una vez que el hidróxido de aluminio no es tóxico. $\mathrm{Su}$ inocuidad, al menos a corto plazo, está suficientemente comprobada por su amplia aplicación en la industria farmacéutica en medicamentos antiácidos.
Antes de pasar a la fase de producción y distribución masiva del hidrogel, queda por estudiar la aceptación del método por parte de la población a la que está destinado. Aunque el hidrogel no confiere al agua ningún sabor desagradable, se desconoce la aceptación del uso diario que pueda tener entre la población que lo utilizaría para tratar el agua de beber. Una vez puesto en práctica el método, se espera obtener una excelente prevención de los trastornos relacionados con el consumo de agua contaminada con arsénico.

\section{REFERENCIAS}

1. Luján JC, Graieb O J. Eliminación del Arsénico en Agua por Destilación a escala doméstica en zonas rurales. Tucumán, Argentina. Revista Médica de Tucumán. 1994;1: 247-255.

2. Luján JC, Graieb OJ. Eliminación del arsénico en agua por destilación a escala doméstica en zonas rurales. Buenos Aires-Argentina. Revista de Ciencia y Tecnología de la Universidad Tecnológica Nacional. 1996; 3:13.

3. De los Ríos EH, Alperovich BA, Luján JC, Juárez MF, Iturre de Aguirre L, López C. Estudio integral del HACRE en la provincia de Tucumán, Buenos Aires, Argentina. Revista Dermatológica Argentina 1984;65: 243-57.
4. Sancha AM. Arsénico en agua potable. Santiago de Chile: Universidad Nacional de Chile; 1982. Publicación 0(16):44-9.

5. Callegaro R, Cusimano N, Deambrosis N, Cotta E. Arsénico, flúor y vanadio en aguas de bebida. Técnicas para corregir su exceso. $5^{\circ}$ Congreso Argentino de Saneamiento. Buenos Aires, Argentina, 1986. Tema 1, No. 7, 1.7.7.38

6. Babor J, Ibarz J. Obtención del hidróxido de aluminio. En: Química general moderna. 7a. ed. Barcelona: Editorial Marín; 1964. p. 747 .

7. American Public Health Association, American Water Works Association, Water Pollution Control Federation. Métodos normalizados para el análisis de aguas potables y residuales. 17a. ed. México, D.F.: Editorial Interamericana S.A.; 1990. Sección 3-83.

8. Juge ON. Utilización de coagulantes en hidrobacteriología. Su arrastre bacteriano y diferente desarrollo en diversos medios de cultivo. $4^{\circ}$ Congreso Argentino de Saneamiento, San Miguel de Tucumán, Argentina, 1974. Publicación Oficial de Trabajos. pp. $473-480$.

Manuscrito recibido el 13 de julio de 2000. Aceptado para publicación, tras revisión, el 4 de abril de 2001.

ABSTRACT Objective. To describe the making of and the preliminary results from an aluminum hydroxide hydrogel that, when added directly to water, can totally eliminate arsenic, regardless of the nature of the water and the oxidation state of the metalloid.

An aluminum hydroxide hydrogel to remove arsenic from water
Methods. The raw materials used to make the aluminum hydroxide hydrogel were: hydrated aluminum sulfate (which is used to make water safe for drinking), calcium hypochlorite in powder form, ammonium hydroxide, and distilled water (when done at the laboratory scale), and water from inverse osmosis of the same or better quality than the distilled water (when done at a pilot scale). Quality control for the finished product consisted of determining its ability to adsorb arsenic and performing bacteriological tests to demonstrate its sterility. The product was used with water samples to which arsenic had been added in the laboratory and with water samples from the province of Tucumán, Argentina, with naturally occurring arsenic. To analyze the arsenic in the water the colorimetric silver diethyldithiocarbamate method was used.

Results. Using the hydrogel greatly reduced the amount of arsenic. Treating both the natural and laboratory-produced arsenical waters yielded arsenic concentrations under the limit ( 0.01 parts per million) that was detectable with the analytical method used. The bacteriological tests of the finished product indicated there were no viable bacteria.

Conclusions. Using the aluminum hydroxide hydrogel produced the desired reduction in the arsenic concentration in the water. This method for removing arsenic is inexpensive and easy to use in scattered rural populations in areas having high arsenic levels and lacking drinkable water, as well as an adequate sanitary and electricpower infrastructure. 